\title{
Self-Genital Mutilation and Attempted Suicide by Cut Throat in the Same Patient at Presentation: A Rare Event
}

\author{
Senyo Gudugbe' ${ }^{1}$, Isaac Asiedu' ${ }^{2}$, Jonathan Lamptey', Mathew Y. Kyei ${ }^{2}$, Kenneth Baidoo ${ }^{3}$ \\ ${ }^{1}$ Department of Surgery, Korle Bu Teaching Hospital, Accra, Ghana \\ ${ }^{2}$ Urology Unit, Department of Surgery, School of Medicine and Dentistry, College of Health Sciences, University \\ of Ghana, Accra, Ghana \\ ${ }^{3}$ Otolaryngology Unit, Department of Surgery, School of Medicine and Dentistry, College of Health Sciences, \\ University of Ghana, Accra, Ghana \\ Email: senyomd@gmail.com
}

Received 10 August 2015; accepted 6 October 2015; published 9 October 2015

Copyright (C) 2015 by authors and Scientific Research Publishing Inc.

This work is licensed under the Creative Commons Attribution International License (CC BY).

http://creativecommons.org/licenses/by/4.0/

(c) (i) Open Access

\begin{abstract}
Genital self-mutilation is an uncommon event that is commonly associated with psychotic disorders. Such injuries have also been reported secondary to complex religious beliefs and delusions regarding sexual guilt. Even though few case reports of male genital self-mutilation are available in literature, it is rare to have a combined self-genital mutilation and attempted suicide by cut throat occurring in the same patient at presentation. We presented the case of a 38-yr-old male who presented to the accident and emergency centre of a tertiary hospital in Accra, Ghana.
\end{abstract}

\section{Keywords}

\section{Self Genital Mutilation, Attempted Suicide, Cut Throat}

\section{Introduction}

Self mutilation has been defined as the deliberate destruction or alteration of body tissue without conscious suicidal intent [1], so though there could be scars on other parts of the body, they are usually from minor superficial lacerations. It has been performed by individuals of all races religions and cultures. The first report in English medical literature of genital self mutilation (GSM) was in 1901 by Strock [2] [3]. The occurrence of genital self mutilation in the absence of psychopathology is extremely rare [4]. Self inflicted genital injuries range from simple lacerations of the external genitalia to more complex injuries such as penile amputation, self castration or 
a combination of both [5]. Suicide is defined as death due to an intentional act or acts of the deceased who anticipates his or her resultant death [6]. It has been observed that cut throat is the most commonly preferred method for committing suicide [7]. Epidemiological studies have established that, patients with background schizophrenia have an 8.5 fold-increased risk for suicide compared to the general population [8] [9]. In this patient, there was genital self mutilation followed by an attempted suicide by cut throat. This rare presentation and the challenges of management are presented in this case report.

\section{Case Summary}

38-yr-old male was referred from a primary health facility where he had presented with a history of an attempted suicide having amputated his glans penis and then cut his throat in sequence. He was found in his apartment bleeding and rushed for medical attention. An estimated two hours had elapsed between time of injury and arrival at the accident and emergency centre. Patient was diagnosed of schizophrenia five years earlier but has been non compliant and off his regular medications (Olanzapine) for a month. The Patient alluded to auditory hallucinations beckoning him to commit suicide although this index presentation was his first attempt. He is separated from the wife and lives alone in a suburb of Accra. He is a Christian who works as a carpenter and has no history of illegal substance use.

On physical examination patient was fully conscious, communicating and pale. His oxygen saturation was 95\% on room air with a respiratory rate of 30 cycles per minute and a mild inspiratory stridor. His Blood pressure was 110/65 mmHg and the pulse was 92 beats per minute regular with good volume. Neck examination revealed a single transverse incision measuring $8 \mathrm{~cm} \times 2 \mathrm{~cm}$ with bleeding edges. The incision extends to the medial edges of both sternocleidomastoids (Figure 1).

Examination of the abdomen and perineum revealed an amputated glans penis, bleeding penile stump and an exposed penile urethra. There were two ventral penile shaft lacerations measuring $1 \mathrm{~cm} \times 0.5 \mathrm{~cm}$ each, limited to the dermis and located $2 \mathrm{~cm}$ and $3 \mathrm{~cm}$ from the peno-scrotal junction. The urethra was not lacerated ventrally (Figure 2). The amputated stump was not brought to the hospital.

The patient was resuscitated with intravenous crystalloids and started on intravenous antibiotics. He was given tetanus prophylaxis. No foreign bodies or subcutaneous emphysema was demonstrated on Lateral soft tissue neck x-ray. Chest $\mathrm{x}$-ray done was normal. Haemoglobin at presentation was $12.4 \mathrm{~g} / \mathrm{dl}$ with a Haematocrit of $40 \%$. Patient was sent to theatre within 4 hours of presentation and had emergency neck and penile exploration under general anaesthesia. Neck findings were a single transverse upper neck incision measuring $8 \mathrm{~cm} \times 2 \mathrm{~cm}$, severed strap muscles exposing the laryngeal prominence, the thyroid cartilage and oedematous vocal chords. The oesophagus was not injured. The carotid sheath and its contents were spared on both sides. Penile findings were an amputated glans penis, two ventral penile lacerations limited to the dermis and located $2 \mathrm{~cm}$ and $3 \mathrm{~cm}$ from the peno-scrotal junction. The urethra was not lacerated ventrally. Surgical procedures performed included laryngeal repair, strap muscle repair and a low tracheostomy by the ENT surgeon. The penile stump was refashioned after a urethral catheter was passed and the ventral lacerations were sutured by the Urologists (Figure 3). A nasogastric tube was passed intra operatively.

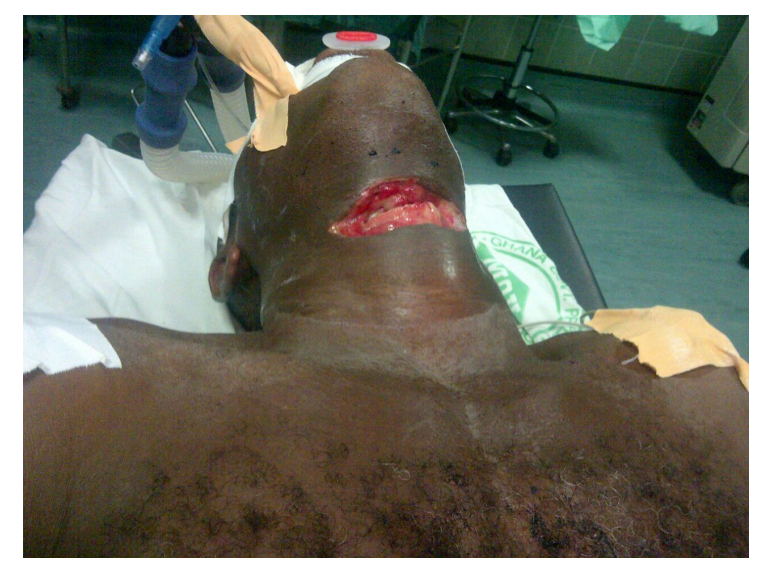

Figure 1. Cut throat. 


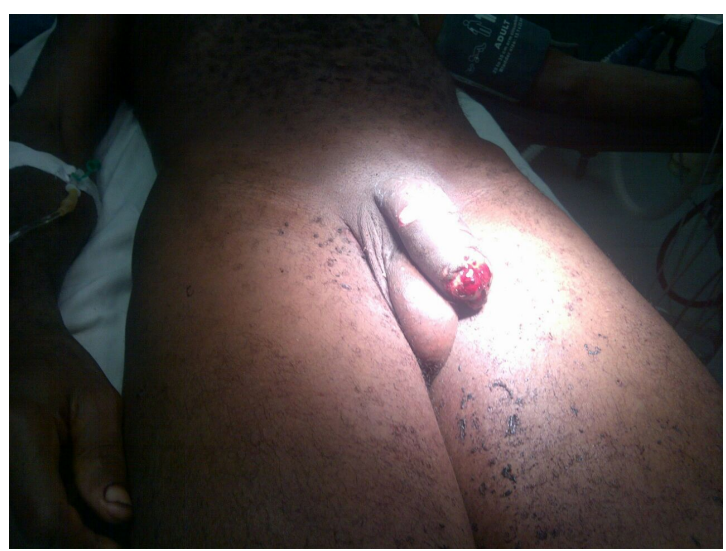

Figure 2. Penile stump,

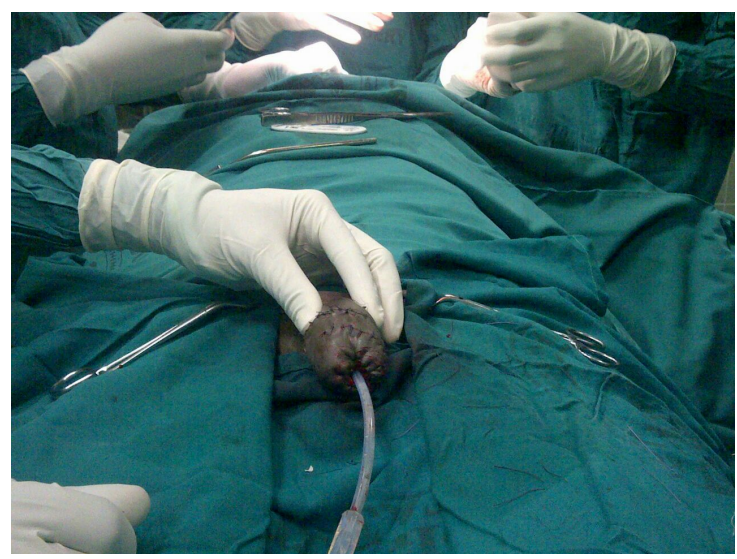

Figure 3. Refashioned Penile stump.

Post operatively patient was fed via the nasogastric tube for the first four days, his neck drain was removed on post operative day (POD) 3 and neck stitches removed POD 5. Flexible laryngoscopy done on POD 6 showed normal vocal cords that abduct and adduct normally, patient had normal breathing and phonation. Patients refashioned penile stump and sutured ventral lacerations healed well, the urethral catheter was removed on POD 6. De-canulation of the tracheostomy was done POD11. Whilst on admission, patient had reassessment by the psychiatrist and the diagnosis of schizophrenia (DSM code 295.3) was confirmed and restarted on Olanzapine. He was discharged home POD 12 after confirming his appointment with the Psychiatrist for the ensuing 3 months.

\section{Discussion}

Self injurious behaviour is observed in both psychotic and nonpsychotic individuals though the self genital mutilation is usually associated with the psychotic disorders. Patients with command hallucinations, religious preoccupations, substance abuse and social isolation are the most vulnerable [10]. Our patient admits to auditory accusatory hallucinations secondary to schizophrenia. Male sex, young age, higher levels of education, depressive symptoms and active hallucinations have been found to be strongly associated with suicide in schizophrenia [11]. Suicide prediction in schizophrenia is complex and efforts on prevention should also focus on ensuring compliance with medications [6]. An effective multidisciplinary team comprising the Psychiatrist, Urologist, and the ENT surgeon should be involved in the management of patients with a background psychotic disorder, self genital mutilation and an attempted suicide by cut throat.

\section{References}

[1] Coons, P.M. (1992) Self-Amputation of the Breasts by a Male with Schizotypal Personality Disorder. Hospital \& 
Community Psychiatry, 43, 175-176. http://dx.doi.org/10.1176/ps.43.2.175

[2] Eke, N. (2000) Genital Self-Mutilation. There is no method in this madness. BJU International, 85, 295-298. http://dx.doi.org/10.1046/j.1464-410x.2000.00438.x

[3] Bhattacharyya, R., Sanyal, D. and Roy, K. (2011) A Case of Klingsor Syndrome: When There Is No Longer Psychosis. Israel Journal of Psychiatry \& Related Sciences, 48, 30-33.

[4] Mareko, G.M., Othienco, C.J., Kuria, M.W., Kiarie, J.N. and Ndetei, D.M. (2007) Body Dysmorphic Disorder. Case report. East African Medical Journal, 84, 450-452.

[5] Stunnel, H., Power, R.E., Floyd, M. Jnr and Quinlan, D.M. (2006) Genital Self Mutilation. International Journal of Urology, 13, 1358-1360. http://dx.doi.org/10.1111/j.1442-2042.2006.01548.x

[6] Horswell, J. (2000) Suspicious Deaths, Encyclopedia of Forensic Sciences. In: Siegel, J.A., Saukko, P.J. and Knupfer, G.C., Eds., Crime Scene investigation and Examination, Academic Press, San Diego, 1, 463.

[7] Marak, F.K. and Singh, Th. B. (2005) Suicidal Cut Throat-A Case Report. JIAFM, 27, 260-262.

[8] Inskip, H.M., Harris, E.C. and Barraclough, B. (1998) Lifetime Risk of Suicide for Affective Disorder, Alcoholism and Schizophrenia. The British Journal of Psychiatry, 172, 35-37. http://dx.doi.org/10.1192/bjp.172.1.35

[9] Harris, E.C. and Barraclough, B. (1997) Suicide as an Outcome for Mental Disorders: A Meta-Analysis. The British Journal of Psychiatry, 170, 205-228. http://dx.doi.org/10.1192/bjp.170.3.205

[10] Tobias, C.R, Turns, D.M, Lippman, S., Parry, R. and Oropilla, T.B. (1988) Evaluation and Management of Self Mutilation. South Medical Journal, 81, 1261-1263. http://dx.doi.org/10.1097/00007611-198810000-00015

[11] Hor, K. and Taylor, M. (2010) Suicide and Schizophrenia: A Systematic Review of Rates and Risk Factors. Journal of Psychopharmacology, 24, 81-90. http://dx.doi.org/10.1177/1359786810385490 